\title{
Early Warning Mechanism of Loess Collapse Based on Stochastic Petri Net: A Case Study in China
}

\author{
Yining Zhang ${ }^{1}$, Lin Zhu ${ }^{1}$, Yuyang Gao ${ }^{1}$, Mengyun Liu ${ }^{1, *}$ and Mengxuan Zhang ${ }^{2}$ \\ ${ }^{I}$ College of Natural Resources and Environment, Northwest A\&F University, Shaanxi 712100, China \\ ${ }^{2}$ Faculty of Engineering, Architecture \& Information Technology, The University of Queensland, St Lucia, QLD 4072, Australia
}

Received 2 September 2021; Accepted 30 November 2021

\begin{abstract}
As a common geological disaster in the Loess Plateau, loess collapse has a huge impact on local industry, agriculture, transportation and water conservancy projects. Loess collapse is due to instability caused by the influence of weather, topography, soil type, human engineering activities and other factors that cause environmental destruction. To reveal the relationship between the collapse of loess and its influencing factors, a calculation model for the probability of loess collapse was proposed in this study. In this study, the causes of loess collapse were analyzed by establishing a multivariate aggregate structure. Stochastic Petri net and its isomorphic Markov chain were applied to examine the collapse process and the accuracy of the model was verified through experiments. Results demonstrate that road network density and soil stability have large utilization rate and great influence on the entire system. The daily temperature difference and daily rainfall below $10{ }^{\circ} \mathrm{C}$ and $30 \mathrm{~mm}$ strongly influence the probability of collapse warning. The change of road network density affects the probability of early warning, but the effect decreases with the increase of density. By examining the early warning mechanism of loess collapse, this study provides a reference value for the prevention and control of other types of loess collapse disasters.
\end{abstract}

Keywords: Loess Collapse, Stochastic Petri Net, Soil Stability, Early Warning Mechanism

\section{Introduction}

Scholars have conducted numerous studies on the regional and monomer analysis of collapse events by establishing mathematical models, physical and mechanical models, or uncertainty models [1] [2]. However, in the case of loess collapse, many deficiencies occur in the comprehensive judgment of the occurrence process, formation mechanism and soil stability due to limitations in the calculation methods and assumptions. Although some studies have been conducted on the quantitative aspects of soil stability evaluation, collapse process reduction, or risk evaluation, current studies on loess collapse mostly focus on the qualitative aspects. With regard to common preventive measures of soil state monitoring, few comprehensive studies have been conducted on early warning mechanisms with external factors such as climate and human engineering activities [3-5]. Obviously, disasters caused by loess collapse are complex and multifactorial and huge technical difficulties are involved in the failure mode [6-9], which brings great challenges to early warning mechanism and prevention and control measures. Considering the extensive loss of disasters, achieving the early warning of loess collapse is necessary.

In this study, the cause of loess collapse in northern Shaanxi is considered as a multivariate set structure. The influencing factors and early warning process are investigated quantitatively quantitatively by using Stochastic Petri Net(SPN) theory and Markov chain, which enable us to scientifically and accurately predict the relationship among the influencing factors and the occurrence probability of disaster loess collapse. This study provides a reference for the prevention and early warning of the collapse disaster.

\section{State of the art}

Scholars have focused on collapse-forming conditions and influencing factors and laws and established early warning models by analyzing the deformation failure characteristics of collapse. Liu[10] classified and summarized the typical loess collapse failure modes in Shanxi and summarized the unstable interface of loess collapse and the corresponding inducing factors ,but mainly focused on the mechanical properties of the soil. Applying the static mechanism, $\mathrm{Hu}$ [11] established the stability-calculating method of various collapse types and proposed the comprehensive prediction method of collapse. Qu et al. [12] studied the clay content of loess and the development degree of loess collapse disaster from the micro point of view. Tang et al. [13-15] determined the scattering range of collapse by using the definitions of collapse angle and extension angle, which is a statistical measurement after the fact and lacks predictability. Xu [16] proposed the concept of displacement tangent angle according to the characteristics of cumulative displacement time curve in various deformation stages of the slope and established the landslide early warning criterion. Liu [17] made a preliminary retrospective analysis on inducement and critical risks of disaster by using the expert assignment method. Peng et al. [18] concluded that the regional tectonic stress was the first driving force applied by the landslide groups on the Loess Plateau and mainly analyzed the changes of the mechanical properties of the soil, which 
caused the deformation rate time curve to become a nondifferentiable curve at the key points without considering other factors and caused difficulty in achieving the advance warning and prediction of sudden loess landslides. Li et al. [19] proposed a collapse detection method based on influencing factors without specific case analyses. Garakani et al. [20] evaluated loess collapse in an unsaturated state and built a model, but only focused on collapsible loess. Zamani et al. [21] evaluated the folding potential of the samples collected at a certain place under different immersion stresses by studying the clay content of folding soil with a 1D integration device and also evaluated the soil stability. Fei et al. [22] analyzed the effects of rainfall conditions and soil characteristics on pore water pressure of slopes by using finite element analysis. Johari et al. [23] found that the likelihood of collapse increased with decreasing water content, dry density and nanoclay content, but no other factors were studied. Assallay et al. [24] studied the formation and stability of fragipans, but mainly focused on the micro scale. Osabank and Staceyt [25] established a slope instability prediction model based on velocity reciprocal method by using a slope monitoring radar, which can effectively predict the failure time in the accelerated deformation stage. Lipiec et al. [26] analyzed changes in the pore size distribution (PSD), stability and water repellency of one-week old compound casts produced by edgier earthworms vs. surrounding natural aggregates in loess soil exhibiting unstable structure. Niemiec et al. [27] considered that surface runoff as a neglected key factor in the past exploration of loess stability and described the measures to control surface runoff as a difficult and dangerous process. Manconi et al. [28] applied the statistical method to set the threshold model to predict La Sax rock landslide in the time window, which is only suitable for short-term prediction. Arabameri et al. [29] invented spiral columns to increase the stability of loess according to the properties of loess soil. Sharma et al. [30] invented a soil nail to increase the friction of soil particles and reduced the probability of soil instability, which damaged the soil ecosystem. By studying the relationship between plant roots and soil stability, Sonal et al. [31] presents the effect of initial placement conditions and flooding stress on the collapse potential of endanger loess. Rahmani et al. [32] found that the introduction of additives, such as lime and other substances, changed the texture of loess and improved its mechanical strength.

The preceding analyses mainly focused on the formation of loess collapse under single factors such as rainfall and soil properties. Most of the multi-factor studies focused on qualitative aspects. The study on the formation process of loess collapse under the comprehensive influence of multiple factors is rare. In this study, the cause of collapse is described as a multivariate aggregate structure. Using the methods of stochastic Petri net and Markov chain, the SPN model of loess collapse in Northern Shaanxi is constructed, the relevant performance parameters of the model are calculated and the formation mechanism of collapse is quantitatively analyzed. At the same time, the dynamic simulation analysis is conducted for the collapse example of Jiaxian County in Northern Shaanxi to study the relationship among daily rainfall, daily temperature difference, road network density and collapse early warning probability, to provide a reference for the prevention and control of loess collapse disasters.

The rest of this study is organized as follows. Section 3 describes the multivariate set structure of loess collapse and establishes the SPN model of early warning in northern Shaanxi based on stochastic Petri net and Markov chain. Section 4 calculates the busy rate of the place and the utilization rate of the transition to analyze the performance of the model according to the specific collapse example, dynamically analyzes the key influencing factors and determines the influence of each factor on the early warning. Section 5 summarizes the conclusions.

\section{Methodology}

\subsection{Loess collapse structure}

The study described the loess collapse as a multivariate aggregate structure: loess collapse accident $=\{$ \{foundation causes $\} \cup\{$ potential causes $\}$, \{inducing causes $\}$ \}. The loess collapse of the multivariate aggregate structure is shown in Fig. 1.

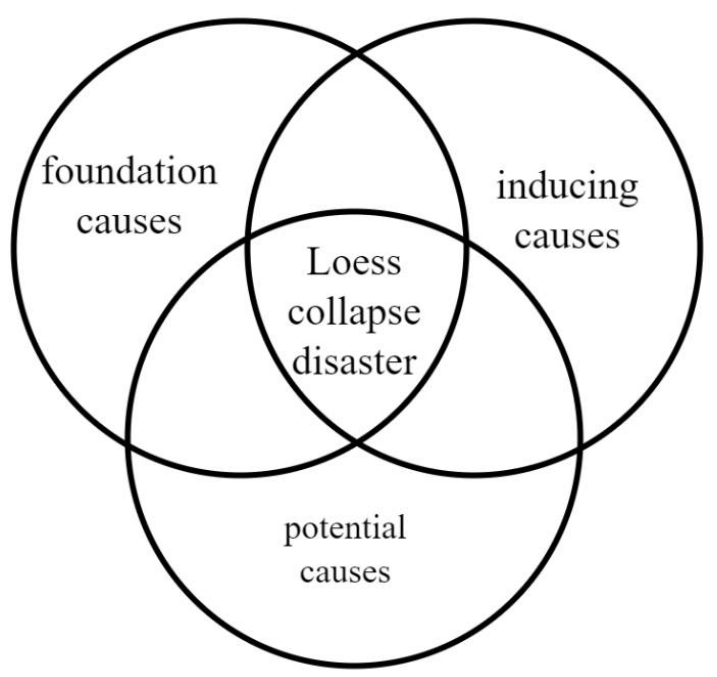

Fig.1. Causes of loess collapse based on multivariate aggregate structure

\subsection{Early warning mechanism of loess collapse disaster}

\subsubsection{Model establishment}

The study established an early warning indicator system for loess collapse disasters based on foundation causes, potential causes and inducing causes, as shown in Fig. 2. 
Yining Zhang, Lin Zhu, Yuyang Gao, Mengyun Liu and Mengxuan Zhang/

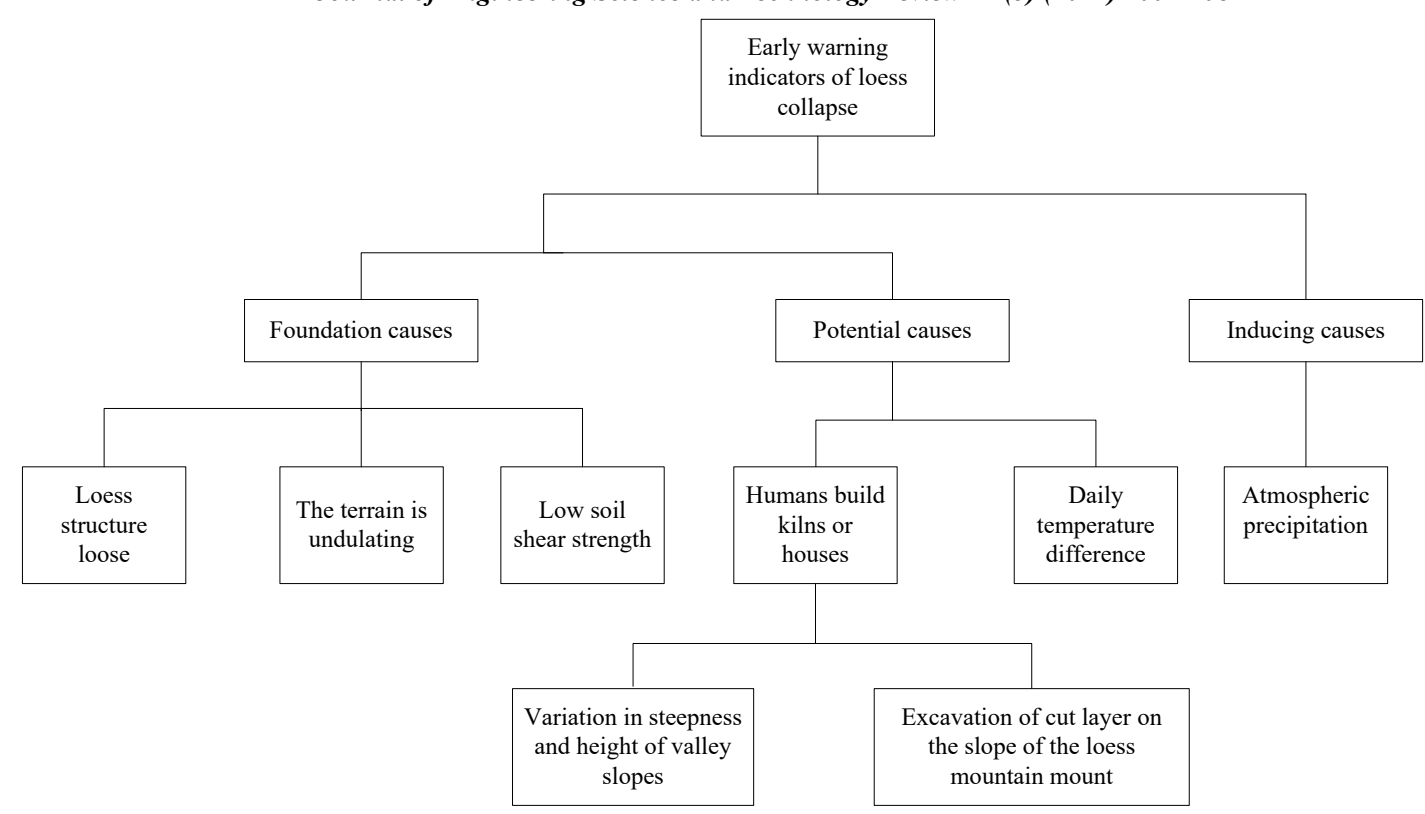

Fig. 2. Early warning indicators of loess collapse disaster

The foundation causes were mainly the structure, topography and stability of the loess itself, which were due to natural conditions and historical man-made actions. The loess could be monitored and evaluated to endow the SPN model an initial value. Among the potential causes, human engineering activities often resulted in the loose structure of loess soil and daily temperature difference caused the soil freeze to thaw. Eventually, when the bearing capacity is not enough to support the gravity of the soil, collapse would occur. Atmospheric precipitation was the main inducing cause of loess collapse. Results demonstrated [1] that many loess collapse accidents were caused by rainfall and high intensity human engineering activities. Among them, meteorological information, such as rainfall and daily temperature difference, could be obtained through meteorological sensors and the intensity of human engineering activities is quantitatively described by road network density, that is, the ratio of the total length of regional roads to the area of the region. The selected roads included highways, national highways, provincial highways, county highways and railways. Referring to the 3D aggregate factor index of loess collapse, an early warning mechanism of loess collapse disaster is designed and shown in Fig. 3.

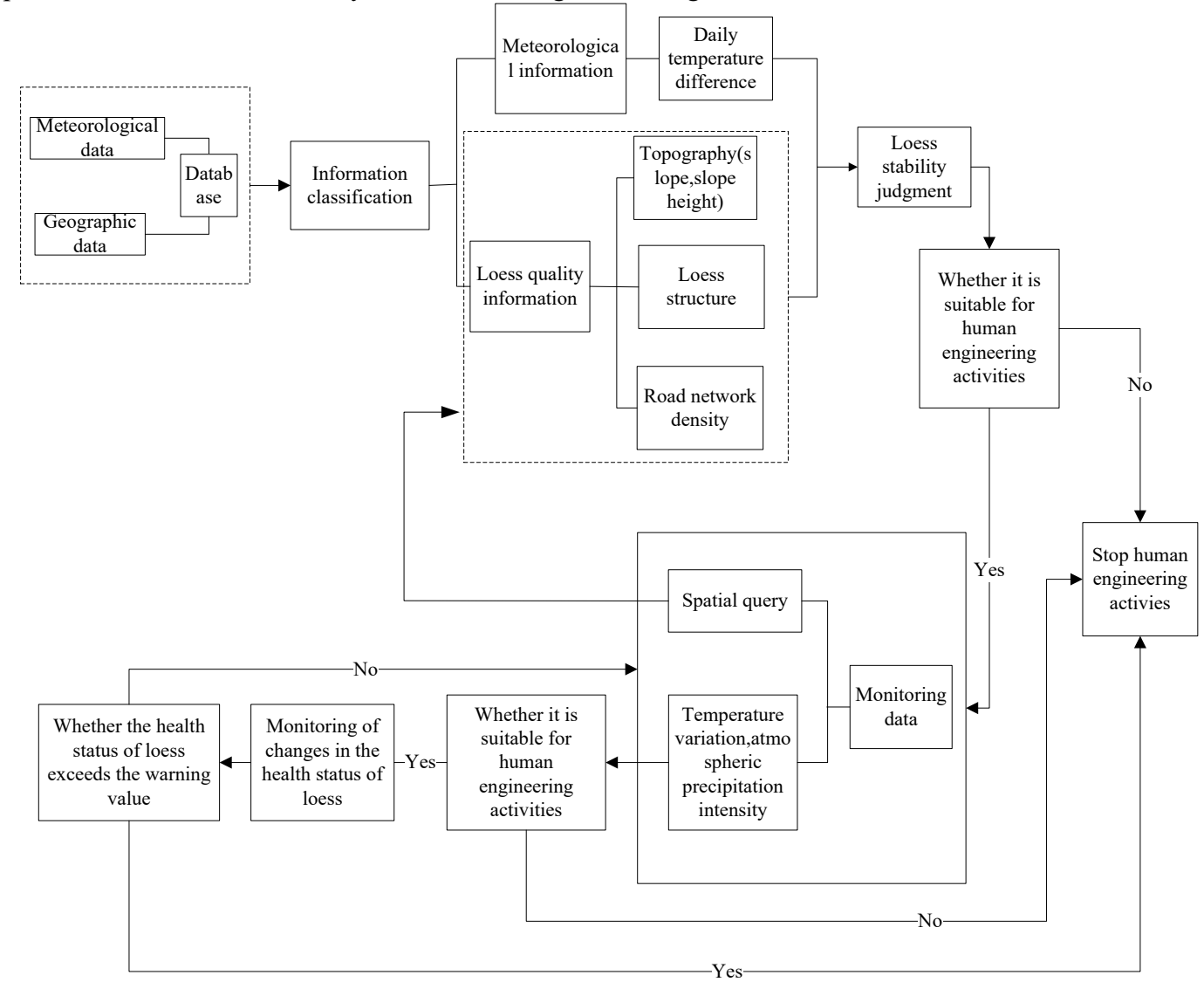

Fig. 3. Early warning mechanism of loess collapse disaster 


\subsubsection{SPN model for early warning of loess collapse} disaster

Loess collapse is a type of dynamic system with rapid occurrence and short time interval. Petri net is a modeling and analytical tool for structured discrete event dynamic system. Petri net accurately describes not only the system structure but also the dynamic behavior of the system in real time, that is, the state change of the system. As the early warning mechanism of loess collapse we are studying is a system that can produce effective warning information, the local population has enough time to protect themselves or withdraw from the disaster area after the danger warning to reduce casualties and losses. Therefore, time is a parameter that needs to be considered in the early warning model. Stochastic Petri net is also called Markov Petri net. SPN regards time as a random variable on the basis of classical Petri net, so that a certain time sequence occurs among the places. Therefore, the study selects stochastic Petri net for analysis.

Stochastic Petri nets is generally defined as a 7-tuple $\left(P, T, F, V, W, M_{0}\right.$, and $\left.\lambda\right): P=\left\{P_{1}, P_{2}, \cdots P_{M}\right\}$ is the non-empty finite set of the place, $T=\left\{t_{1}, t_{2}, \cdots t_{m}\right\}$ a finite set of transitions,
$F \in\{P \times T\} U\{T \times P\}$ represents the set of directed arc elements connecting the elements of the place and the elements of transition, $V \in P \times T$ is the forbidden arc of transition, $W: F \rightarrow N$ is the arc weight function, $N=\{1,2,3 \cdots\}, M_{0}$ mapping from $P \rightarrow N_{0}, \quad N_{0}=\{1,2,3 \cdots\} \quad$ means the set of markings and $\lambda=\left\{\lambda_{1}, \lambda_{2}, \cdots \lambda_{M}\right\}$ is the average ignition efficiency of the transition.

The instantaneous transition is associated with a random switch with zero ignition delay and the time transition obeys a negative exponential distribution.

According to the early warning mechanism of loess collapse disaster in Fig. 3, the study divided the place and transition through the analysis of the loess collapse process and expressed the various discrete factors that affect the probability of loess collapse in chronological order. The SPN model is finally constructed as shown in Fig. 4 and the elements are defined in Table 1 . The model consisted of 8 places and 10 transitions and the meanings of each place and transition are shown in Tables 2 and 3.
Fig. 4. SPN model of loess collapse disaster early warning process

Table 1. Petri net elements

\begin{tabular}{c|c}
\hline Petri net elements & Meanings \\
\hline Place $\mathrm{P}$ & Resource Status \\
Transition $\mathrm{t}$ & Resource Changes \\
Token & Number of resources (the item \\
Initial marking 0 or 1 in a random Petri net) & Initial state of resource
\end{tabular}

Table 2. Definitions of places

\begin{tabular}{c|c}
\hline Place & Definition \\
\hline$P_{1}$ & Meteorological datasets \\
$P_{2}$ & Geographic datasets \\
$P_{3}$ & Information integration \\
$P_{4}$ & Loess in poor condition \\
$P_{5}$ & Human overexploitation of loess \\
$P_{6}$ & Loess condition deterioration \\
$P_{7}$ & Elevated risk of loess collapse \\
$P_{8}$ & Crisis warning \\
\hline
\end{tabular}

Table 3. Definitions of transitions

\begin{tabular}{c|c}
\hline Transition & Definition \\
\hline$t_{1}$ & Database update \\
$t_{2}$ & Average monthly temperature difference \\
$t_{3}$ & for a month over the years \\
$t_{4}$ & Slope assessment \\
$t_{5}$ & Slope height assessment \\
$t_{6}$ & Road network density \\
$t_{7}$ & Increased daily temperature difference \\
$t_{8}$ & Occurrence of atmospheric precipitation \\
$t_{9}$ & Atmospheric daily precipitation \\
$t_{10}$ & Tendency toward loess collapse \\
\end{tabular}

The initial marking of this system was $M_{1}=[1,1,0,0,0,0]$, which meant that each of the $P_{1}$ and $P_{2}$ places contained a token and the other places did not. In Fig. 3, the loess collapse early warning process diagram represented the acquisition of meteorological data and geographic data. 
Yining Zhang, Lin Zhu, Yuyang Gao, Mengyun Liu and Mengxuan Zhang/

Journal of Engineering Science and Technology Review 14 (5) (2021) 100 - 108

According to the initial marking and SPN model shown in Fig. 4, the reachable set obtained by different transitions was calculated. When the transition satisfied the conditions of occurrence, the token moved from the corresponding input place to the output place and the model generated a new state. Based on the initial state $M_{1}$ as the starting point, the set of all states that could be reached was calculated and then the reachable marking Table 4 was obtained.

Table 4. Reachable marking of SPN for early warning process of loess collapse disaster

\begin{tabular}{|l|l|l|l|l|l|l|l|l|}
\hline & $P_{1}$ & $P_{2}$ & $P_{3}$ & $P_{4}$ & $P_{5}$ & $P_{6}$ & $P_{7}$ & $P_{8}$ \\
\hline$M_{1}$ & 1 & 1 & 0 & 0 & 0 & 0 & 0 & 0 \\
\hline$M_{2}$ & 0 & 0 & 1 & 0 & 0 & 0 & 0 & 0 \\
\hline$M_{3}$ & 0 & 0 & 1 & 0 & 0 & 0 & 0 & 0 \\
\hline$M_{4}$ & 0 & 0 & 1 & 0 & 0 & 0 & 0 & 0 \\
\hline$M_{5}$ & 0 & 0 & 0 & 1 & 0 & 0 & 0 & 0 \\
\hline$M_{6}$ & 0 & 0 & 0 & 0 & 1 & 0 & 0 & 0 \\
\hline$M_{7}$ & 0 & 0 & 0 & 0 & 1 & 0 & 0 & 0 \\
\hline$M_{8}$ & 0 & 0 & 0 & 0 & 0 & 1 & 0 & 0 \\
\hline$M_{9}$ & 0 & 0 & 0 & 1 & 0 & 1 & 1 & 0 \\
\hline$M_{10}$ & 0 & 0 & 0 & 0 & 0 & 0 & 0 & 1 \\
\hline
\end{tabular}

The SPN model has an isomorphic Markov chain. Thus, the corresponding Markov chain could be constructed by solving the reachable set of SPN, as shown in Fig. 5. When the constructed Markov chain had a stable distribution, the stable state probability of the system could be obtained. Among them, the directed arc in Fig. 5 represented the transition process from one state of the SPN model to another state and the average implementation efficiency of each transition of the SPN model was taken as $\lambda=\left\{\lambda_{1}, \lambda_{2}, \cdots \lambda_{m}\right\}$, as shown in Fig. 5.

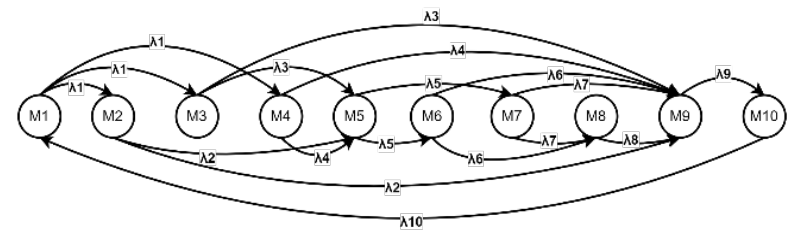

Fig. 5. Isomorphic Markov chain of SPN model for early warning of loess collapse disaster

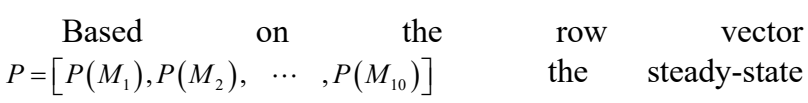
probability of each marking was represented. According to the related theorem of Markov chain stationary distribution and Chepman-Kolmogorov equation:

$$
\left\{\begin{array}{l}
P Q=0 \\
\sum_{i=1}^{10} p\left(M_{i}\right)=1
\end{array}\right.
$$

In Equation (1), the matrix $Q$ was the rate transition matrix of the Markov chain and the off-diagonal element $q_{i j}(i \neq j)$ in the matrix $Q$ depended on the state diagram of the Markov chain system. When a directed arc was observed from the marking $M_{i}$ to the marking $M_{j}$ in Fig. 5, $q_{i j}$ was the implementation rate value on the arc. When there was no arc, $q_{i j}$ was zero. Then, the elements on the diagonal of the matrix $Q$ are as follows:

$q_{i j}=-\sum_{i \neq j} q_{i j}$

Equation (1) and Fig. 5 show the relationship between the Markov chain and probability of the system state, where the result is as follows:

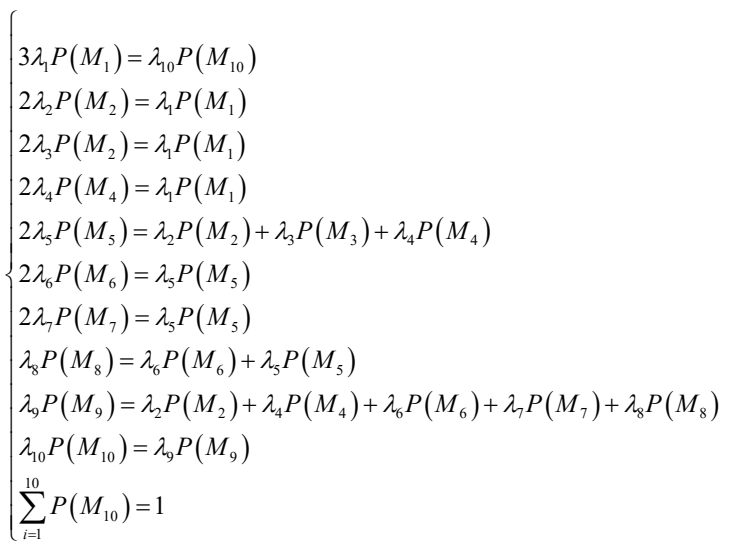

Substituting the data on November 5, 2021 in various regions of northern Shaanxi into Equation (3), the probability distribution of loess collapse in northern Shaanxi on that day was obtained, as shown in Fig. 6.

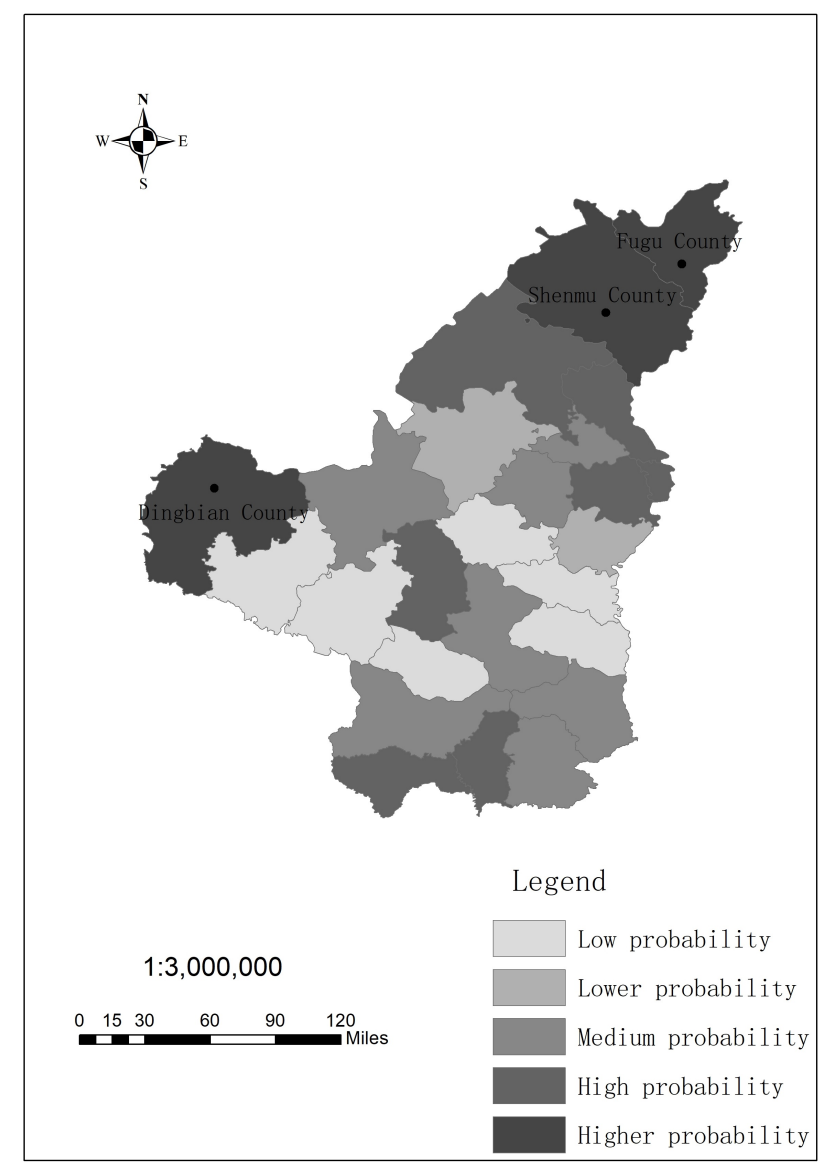

Fig. 6. Probability distribution of collapse in northern Shaanxi

As shown in Fig. 6, the probability of loess collapse in Fugu, Shenmu and Dingbian counties on November 5 was 
Yining Zhang, Lin Zhu, Yuyang Gao, Mengyun Liu and Mengxuan Zhang/

Journal of Engineering Science and Technology Review 14 (5) (2021) 100 - 108

higher than that in other regions. On that day, only the three regions above in northern Shaanxi had atmospheric precipitation, indicating that the probability calculation results were reasonable.

\subsubsection{Test of SPN model for early warning of loess collapse disaster}

The receiver operating characteristic (ROC) curve graph is a curve reflecting that reflects the relationship between sensitivity and specificity. The accuracy of the SPN model prediction was verified by plotting the ROC curve of the probability of loess collapse and calculating the area of the graph below the curve. The probability of disaster occurrence under the SPN model was determined on the basis of the Chepman-Kolmogorov equation and the collection of relevant meteorological, topographic and human activities and other data when the loess collapse occurred in northern Shaanxi. The ROC curve was created by combining the obtained probabilities of disaster occurrence with actual occurrences using SPSS software, as shown in Fig. 7.

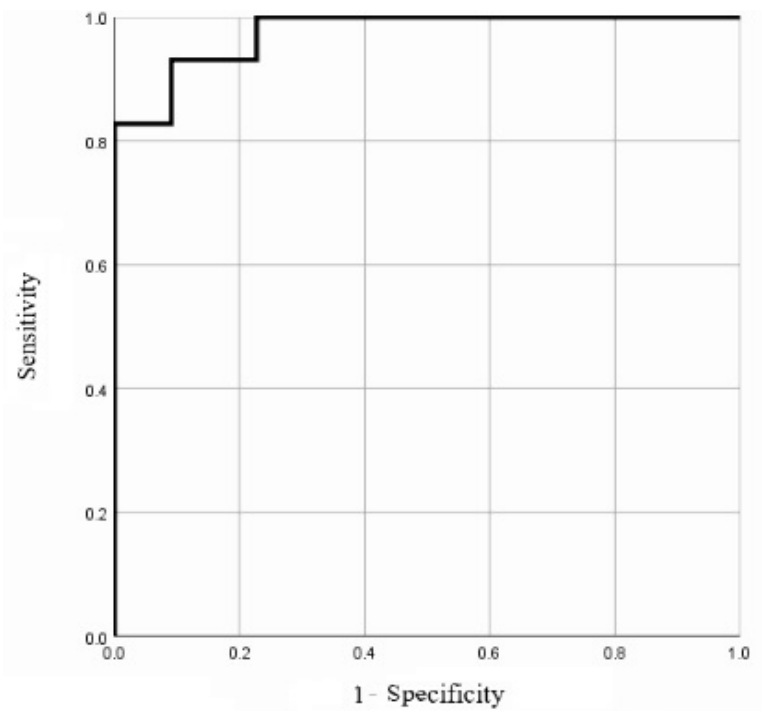

Fig. 7. ROC curve

We calculated the Area Under Curve(AUC) of the ROC curve and got obtained AUC $=0.975>0.85$, which meant that the SPN early warning model had passed the test.

\section{Result Analysis and Discussion}

\subsection{Experimental settings}

On October 26, 2019, at around 7:00 am, a sudden loess collapse occurred in Gaolijiagou Village, Mutouyu Town, Jiaxian County in northern Shaanxi Province. The collapsed area was approximately 500 cubic meters. Dozens of casualties were reported, four houses collapsed, three people were killed and the social influence was bad. According to the DEM data of northern Shaanxi, highway vector data and the official website of the Jiaxian government, the ignition efficiency of each transition when the disaster occurred was calculated, as shown in Table 5.

Table 5.Transition ignition efficiency

\begin{tabular}{c|c|c}
\hline $\begin{array}{c}\text { Ignition } \\
\text { efficiency }\end{array}$ & $\begin{array}{c}\text { Valu } \\
\text { e }\end{array}$ & Meaning \\
\hline$\lambda_{1}$ & 3 & Database update once every three months \\
$\lambda_{2}$ & 11 & Multi-year average temperature difference
\end{tabular}

\begin{tabular}{|c|c|c|}
\hline$\lambda_{3}$ & 9.77 & $\begin{array}{c}\text { in October in Jiaxian Country }\left({ }^{\circ} \mathrm{C}\right) \\
\text { Slope of Jia County }\left({ }^{\circ}\right)\end{array}$ \\
\hline$\lambda_{4}$ & 20.52 & Slope height of Jiaxian County (m) \\
\hline$\lambda_{5}$ & 0.17 & Road network density of Jiaxian County \\
\hline$\lambda_{6}$ & 20.8 & $\begin{array}{l}\text { Daily temperature difference in Jiaxian } \\
\text { County when collapse occurred }\left({ }^{\circ} \mathrm{C}\right)\end{array}$ \\
\hline$\lambda$ & 1 & Atmospheric precipitation \\
\hline$\lambda_{8}$ & 70 & $\begin{array}{l}\text { Daily rainfall in Jiaxian County during } \\
\text { collapse }(\mathrm{mm})\end{array}$ \\
\hline$\lambda_{9}$ & 1 & Abnormal soil stability \\
\hline$\lambda_{10}$ & 1.5 & Warning start \\
\hline
\end{tabular}

According to the proposed calculation method of the probability of each state of the system in 3.3.2, by substituting the data in Table 5 into equation (3), the stability probability of each state was obtained as shown in Table 6 .

Table 6. Stability probability of each state

\begin{tabular}{c|c}
\hline State & Probability value \\
\hline$P\left(M_{1}\right)$ & 0.0324 \\
$P\left(M_{2}\right)$ & 0.0044 \\
$P\left(M_{3}\right)$ & 0.0050 \\
$P\left(M_{4}\right)$ & 0.0023 \\
$P\left(M_{5}\right)$ & 0.4296 \\
$P\left(M_{6}\right)$ & 0.0018 \\
$P\left(M_{7}\right)$ & 0.0365 \\
$P\left(M_{8}\right)$ & 0.0010 \\
$P\left(M_{9}\right)$ & 0.2921 \\
$P\left(M_{10}\right)$ & 0.1947 \\
\hline
\end{tabular}

\subsection{Performance index analysis}

On the basis of obtaining the stable probability of each state, the basic performance indicators of the system were analyzed.

\subsubsection{Busy rate of places}

The busy rate of places refers to the probability of resource flow in various warehouses when the system is in a stable state. In fact, it indicates the probability that each link in the loess collapse early warning system is busy. The busy rate of each place is the sum of the stable probability of each marking state where resources exist in the place as follows:

$$
P\left\{M\left(P_{i}\right)=1\right\}=\sum_{j} P\left\{M_{j}\right\}
$$

The busy rate of each place is calculated according to formula (3), as shown in Table 7.

Table 7. Busy rates of each place

\begin{tabular}{c|c}
\hline Place & Busy rate \\
\hline$P_{1}$ & $P\left\{M\left(P_{1}\right)=1\right\}=P\left(M_{2}\right)=0.0324$ \\
$P_{2}$ & $P\left\{M\left(P_{2}\right)=1\right\}=P\left(M_{1}\right)=0.0324$ \\
$P_{3}$ & $P\left\{M\left(P_{2}\right)=1\right\}=P\left(M_{1}\right)+P\left(M_{2}\right)+P\left(M_{3}\right)=0.0117$ \\
$P_{4}$ & $P\left\{M\left(P_{4}\right)=1\right\}=P\left(M_{5}\right)+P\left(M_{9}\right)=0.7217$ \\
$P_{5}$ & $P\left\{M\left(P_{5}\right)=1\right\}=P\left(M_{6}\right)+P\left(M_{7}\right)=0.0383$ \\
$P_{6}$ & $P\left\{M\left(P_{6}\right)=1\right\}=P\left(M_{8}\right)+P\left(M_{9}\right)=0.2931$ \\
$P_{7}$ & $P\left\{M\left(P_{7}\right)=1\right\}=P\left(M_{9}\right)=0.2921$ \\
$P_{8}$ & $P\left\{M\left(P_{8}\right)=1\right\}=P\left(M_{10}\right)=0.1947$ \\
\hline
\end{tabular}

\subsubsection{Transition usability}

The utilization of transitions refers to the sum of the stable probability values of all markings that can occur. It represents the actual utilization rate of each influencing factor in the early warning system of loess collapse. The 
utilization rate of each change in this study is shown in Table 8:

Table 8.Transition usability

\begin{tabular}{c|c|c}
\hline Transition & Utilization rate algorithm & $\begin{array}{c}\text { Transition } \\
\text { usability }\end{array}$ \\
\hline$t_{1}$ & $P\left(M_{1}\right)$ & 0.0324 \\
$t_{2}$ & $P\left(M_{2}\right)$ & 0.0044 \\
$t_{3}$ & $P\left(M_{3}\right)$ & 0.0050 \\
$t_{4}$ & $P\left(M_{4}\right)$ & 0.0023 \\
$t_{5}$ & $P\left(M_{5}\right)$ & 0.4296 \\
$t_{6}$ & $P\left(M_{6}\right)$ & 0.0018 \\
$t_{7}$ & $P\left(M_{7}\right)$ & 0.0365 \\
$t_{8}$ & $P\left(M_{8}\right)$ & 0.0010 \\
$t_{9}$ & $P\left(M_{9}\right)$ & 0.2921 \\
$t_{10}$ & $P\left(M_{10}\right)$ & 0.1947 \\
\hline
\end{tabular}

Table 8 shows that the utilization rate of transitions 5 and 9 is relatively high, indicating that the activities represented by these transitions play an important role in the early warning system and more time and energy are spent. Thus, the supervision of these two links should be strengthened to ensure the normal operation of early warning work.

\subsection{Single-factor dynamic analysis}

Through the static analysis of the various factors of the collapse system, the influence of each link on the start of the collapse warning could be obtained according to the stability probability of each state. In addition, a single factor can be dynamically analyzed based on stability probability. Compared with other influencing factors, the daily temperature difference and rainfall change greatly over time and the road network density is highly artificially interfered. Therefore, to provide a reference for disaster early warning more effectively, the study obtained the change of stability probability of each state by changing the daily temperature difference, rainfall and road network density data, thereby proposing a scientific early warning specification for loess collapse disaster.

\subsubsection{Influence of daily rainfall on warning probability}

The experiment first considered the influence of the daily rainfall in various situations on the stability probability of each state. The results are shown in Fig. 8.

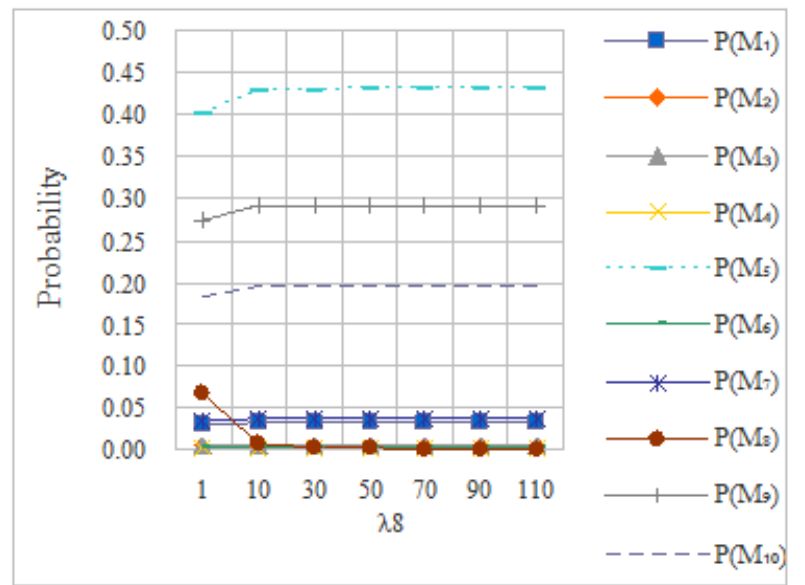

Fig. 8. Influence of daily rainfall on each steady-state probability
As shown in Fig. 8, with the increase of daily rainfall, the value of collapse warning probability $\left(P\left(M_{1}\right)\right)$ increases. In the stage less than $10 \mathrm{~mm}$, the early warning probability increases rapidly, the growth slows down in the $10-30 \mathrm{~mm}$ stage and the early warning probability above $30 \mathrm{~mm}$ is almost unchanged. This result shows that when the daily rainfall is below $30 \mathrm{~mm}$, it has a stronger impact on the early warning probability of collapse and when it is greater than $30 \mathrm{~mm}$, the probability of collapse is greatly affected by other factors.

\subsubsection{Influence of daily temperature difference on} warning probability

Subsequently, through the simulation experiment of the daily temperature difference, the changes of the stability probability of each state under various conditions were obtained as shown in Fig.9.

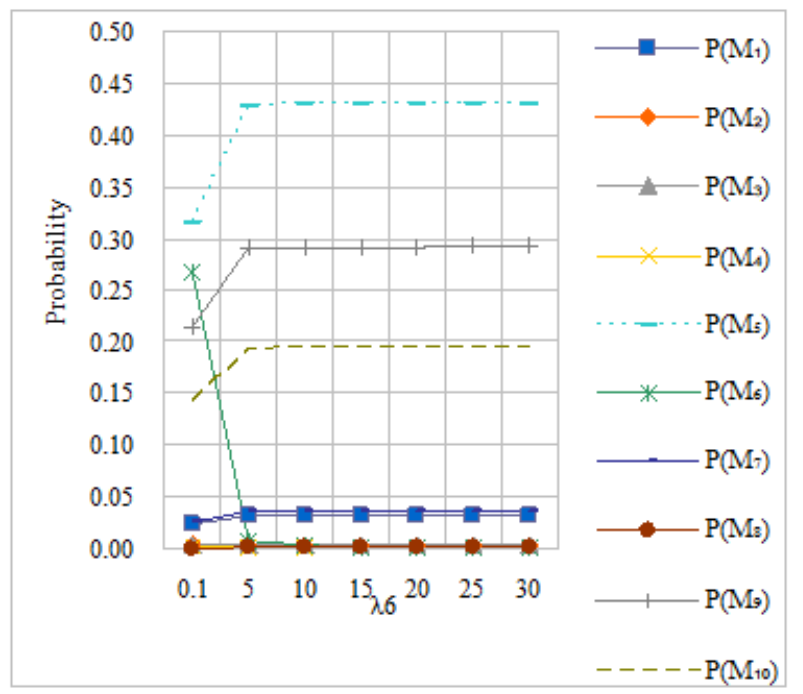

Fig. 9. Influence of daily temperature difference on each steady-state probability

Fig. 9 shows that the influence of daily temperature difference on the early warning probability is similar to that of daily rainfall: with the increase of daily temperature difference, the early warning probability of collapse increases first and then remains unchanged. In the stage below $5{ }^{\circ} \mathrm{C}$, the early warning probability increases rapidly with the increase of daily temperature difference. At $5{ }^{\circ} \mathrm{C}-$ $10{ }^{\circ} \mathrm{C}$, the early warning probability increases slowly. After $10{ }^{\circ} \mathrm{C}$, the probability of early warning is almost unchanged with the increase of daily temperature difference, which shows that when the daily temperature difference is greater than $10{ }^{\circ} \mathrm{C}$, the change of this factor hardly affects the warning probability.

\subsubsection{Influence of road network density difference on warning probability}

Finally, by changing the numerical value of the road network density, we obtained the influence of the strength of human engineering activities on the probability of collapse warning, as shown in Fig. 10.

As reported in Fig. 10, the increase in road network density has a direct impact on the probability of collapse warning. When the road network density is less than $0.2 \mathrm{~km} / \mathrm{km}$, the warning probability increases at a faster rate as the road network density increases and the density is greater than $0.2 \mathrm{~km} / \mathrm{km}^{2}$, the warning probability still increasing, but the rate slower. A comparison of Figs. 8, 9 and 10 show that the road network 
density has a slightly stronger impact on the hazard probability $P\left(M_{1}\right)$ and collapse warning probability of loess soil $P\left(M_{10}\right)$ than the daily rainfall and daily temperature difference. This finding shows that human populations should reduce the intensity of engineering activities to reduce the probability of loess collapse.

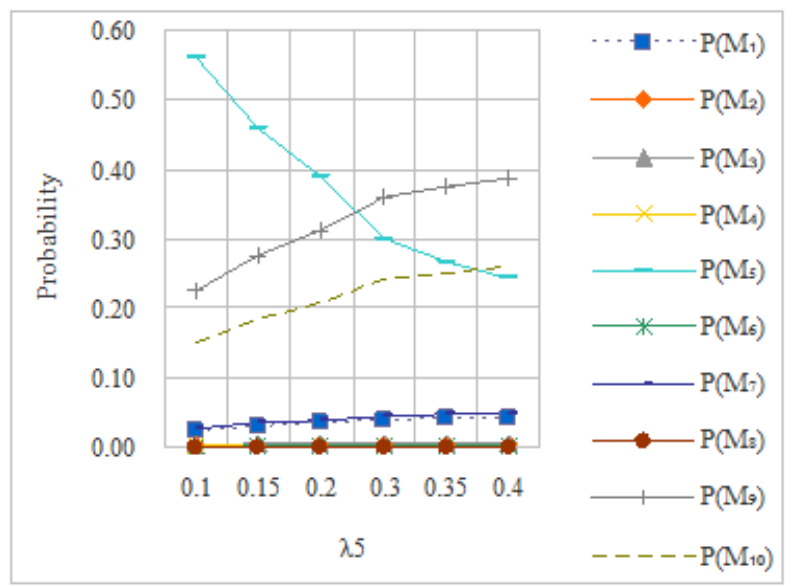

Fig. 10. Influence of road network density on each steady-state probability

\section{Conclusion}

To respond in advance to the occurrence of loess collapse so that casualties and losses can be reduced, the study applied a combination of the establishment of a stochastic Petri net and simulation example analysis to estimate the probability of disaster loess collapse and conduct static and dynamic analysis of the cause, early warning mechanism. The following conclusions can be drawn:

(1) According to the analysis results of the basic indicators of the model, it is easy to block the information in the three processes of whether the health status of loess is poor, whether the collapse condition is deteriorated and whether the risk of loess collapse is elevated, which should take more time and energy.
(2) With the increase of daily rainfall and daily temperature difference, the probability of collapse warning increases first and remains unchanged when the two indicators reach $30 \mathrm{~mm}$ and $10^{\circ} \mathrm{C}$, respectively.

(3) Road network density has a greater impact on collapse probability than the aforementioned two factors. With the increase of road network density, the growth rate of early warning probability continues to decrease, but maintains an increasing trend. Therefore, relevant departments should reduce the intensity of human engineering activities to reduce the probability of collapse.

The study analyzed and described the causes of loess collapse in a multivariate aggregate structure. Based on the analysis results, the early warning index system of loess collapse was proposed and the early warning mechanism in northern Shaanxi was established. Considering the influence of geological conditions, meteorological factors and human engineering activities, the SPN model of loess collapse was established by introducing stochastic Petri net theory to quantitatively describe the probability of loess collapse. The established model scientifically and comprehensively describes the early warning mechanism of loess collapse in northern Shaanxi, providing decision-making basis and data support for disaster prevention, as well as a reference for other disaster warnings. Due to the lack of on-site terrain data, a certain deviation occurs in the probability calculation of specific locations. Therefore, in future research, the accuracy of the early warning method of loess collapse probability can be improved by combining the field terrain data with the stochastic Petri net established in this study.

\section{Acknowledgements}

This work was supported by the Design and Establishment of Early Warning System for Loess Collapse in Northern Shaanxi Based on Stochastic Petri Net (S202110712500).

This is an Open Access article distributed under the terms of the Creative Commons Attribution License.

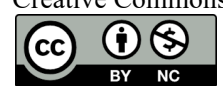

\section{References}

1. Wang, Y. H., "Formation mechanism of loess collapse and selection of prevention and control parameters in a certain area of Shanxi Province". Western-China Exploration Engineering, 33(7), 2021, pp.25-28.

2. Hu, X. X., Dang, J. Q., "Stability Analysis of Tensile Cracking Sliding Loess Collapse Based on Catastrophe Series Method".Hydropower and Energy Sciences, 39(3), 2021, pp.129133.

3. Hu, X. X., "Research on deformation and failure mechanism and monitoring and early warning of collapse disasters". Master thesis of Northwest Agricultural and Forestry University, 2020, pp.10-17.

4. Wang, Y. P., "Research on deformation and failure mechanism and monitoring and early warning of collapse disasters". Doctoral Dissertation Chengdu University of Technology, 2016, pp.128-178.

5. Feda, J., "Collapse of loess upon wetting". Engineering Geology, 25(2-4), 1988, pp.263-269.

6. Shao, S. J., Yu, Q. G., Long, J. Y., "Stress-strain relationship with soil structural parameters of collapse loess". Frontiers of Architecture \& Civil Engineering in China, 2(2),2008,pp.151-160.

7. Duan, Z., Peng, J. B., Chen, W., Zhang, N., Tang, H., "Distribution Difference of Landslide and Collapse in the Loess Tableland Area at the Downstream of Jing River". Northwestern Geology, 51(03), 2018, pp.214-222.
8. Guo, W. X., Li, J. C., Yin, G. S., "Analysis and prediction of loess bank collapse in key circumstances of Xiaolangdi reservoir area”. Inner Mongolia Environment Sciences, 29(10), 2017, pp.206-208.

9. Zourmpakis,A.,Boardman,D.I.,Rogers,C.D.F., "Case study of a loess collapse field trial in Kent, SE England". Quarterly Journal of Engineering Geology and Hydrogeology, 39(2), 2006, pp.131-150.

10. Liu,X.Y., "Failure modes and early identification of typical loess collapse in Shanxi". Journal of Yangtze River Scientific Research Institute,36(11),2019,pp.69-75.

11. $\mathrm{Hu}, \mathrm{H} . \mathrm{T}$. ., "Research on the collapse and falling stone". Journal of Railway Engineering Society, 000(0z1), 2005, pp.387-391.

12. Qu, Y. X., Zhang, Y. S., Chen, Q. L., "Preliminary study on loess slumping in the area between northern Shanxi and western Shanxi-Taking the Pipeline for transporting gas from West to East in china”. Journal of Engineering Geology, 9(3), 2001, pp.233-240.

13. Tang, Y. M., Xue, Q., Bi, J. Y., Cheng, X. J., "The construction of factors for assessing the risk of collapse at loess slopes in northern Shanxi Province". Geological Bulletin, 31(6), 2012, pp.979-988.

14. Tang, Y. M., Xue Q., Li, Z. G., Feng, W., "Loess Landslide Monitoring and Early-warning Methods and Practices on Scale of Single Slope and Regional Scope". Journal of Catastrophe, 30(4), 2015, pp.91-95. 
Yining Zhang, Lin Zhu, Yuyang Gao, Mengyun Liu and Mengxuan Zhang/

Journal of Engineering Science and Technology Review 14 (5) (2021) 100 - 108

15. Qiao, P. T., Tang, Y. M., Zhang, C. L., Kang, H. W., Zhou, X. L., "Catastrophic Analysis of Loess Landslide Considering Unsaturated Seepage under Rainfall Condition". Henan Science, 37(02), 2019, pp.255-261.

16. Xu, Q., Zeng, Y. P., Qian, J. P., Wang, C. J., He, C. J., "Study on a improved tangential angle and the corresponding landslide prewarning criteria". Geological Bulletin of China , 28(4), 2009, pp.501-505.

17. Liu, C. Z., " Analysis methods on the risk identification of landslide disasters". Journal of Engineering Geology, 27(1), 2019, pp.88-97.

18. Peng, J. B., Wang, Q. Y., Zhuang, J. Q., Leng, Y. Q., Fan, Z. J., Wang, S. K., "Dynamic mechanism of landslide disaster formation on the Loess Plateau". Chinese Journal of Geomechanics, 26(5), 2020, pp.714-730.

19. Li, W., "Research on monitoring methods of collapse and landslide geological disasters in loess area". HuaBei Natural Resources, 000(003), 2019, pp.73-74.

20. Garakani, A. A., Haeri, S. M., Desai, C. S., Ghafouri, S. M., Hosein, S., Sadollahzadeh, B., Senejani, H. H., "Testing and Constitutive Modeling of Lime-Stabilized Collapsible Loess. II: Modeling and Validations". International Journal of Geomechanics, 19(4), 2019, pp.1532-3641.

21. Zamani, M., Badv, K., "Assessment of the Geotechnical Behavior of Collapsible Soils: A Case Study of the Mohammad-Abad Railway Station Soil in Semnan". Geotechnical and Geological Engineering, 37(4), 2019, pp.2847-2860.

22. Fei,C., Keizo, U., "Numerical Analysis of Rainfall Effects on Slope Stability ". Journal of Geomechanics, 4(2), 2004, pp.69-78.

23. Johari, A., Golkarfard,H., Davoudi,F.,Fazeli,A., "A predictive model based on the experimental investigation of collapsible soil treatment using nano-clay in the Sivand Dam region, Iran". Bulletin of Engineering Geology and the Environment, 80(9), 2021, pp.6725-6748.
24. Assallay,A.M., Jefferson,I., Rogers,C.D.F., Smalley,I.J., "Fragipan formation in loess soils: development of the Bryant hydroconsolidation hypothesis". Geoderma: An International Journal of Soil Science, 83(1/2), 1998,pp.1-16.

25. OSASANK S., STACETYT R., "Automatic prediction of time to failure of openpitmine slopes based on radar monitoring and inverse velocity method". International Journal of Mining Science and Technology, 2014(24), 2014, pp.275-280.

26. Lipiec, J., Turski, M. H., Hajnos, M., Swieboda, R., "Pore structure, stability and water repellency of earthworm casts and natural aggregates in loess soil". Geoderma:A Global Journal of Soil Science, 243/244, 2015, pp.124-129.

27. Niemiec, D., Marschalko, M., Yilmaz, I.,Cheng,X.F., "Surface runoff on loess: an example of a commonly overlooked hazardous process from northeast Czech Republic". Bulletin of engineering geology and the environment, 78(8), 2019, pp.5841-5851.

28. Manconi A., Giordan D., "Landslide early warning based on failure forecast models: the example of the Mt. de La Saxe rockslide Northern Italy".Natural Hazards and earth System Sciences, 15(7),2015,pp.1639-1644.

29. Arabameri, M., Eslami, A., "Microstructure and Strength Effect on Bearing Capacity of Helical Piles Installed in Golestan Loess". International Journal of Civil Engineering, 19(8), 2021, pp.923940.

30. Sharma, P., Rawat, S. ,Gupta, A.K., "Horizontal Pullout Behavior of Novel in Frictional Soil". International Journal of Civil Engineering,18(10), 2020, pp.1179-1194.

31. Sonal,S.,Radhey,S.S.,Phanikumar,B.R., "A laboratory study of collapse behaviour of remoulded loess under controlled wetting and flooding". Geomechanics and Geoengineering,11(2), 2015, pp.159163.

32. Rahmani, A., Hazzab, A., Aimer, H.,Ghenaim,A., Tefous,A., "Improvement of physical-chemical and Rheo-logical properties of ghardaia loess(southern algeria)using bentonite clay and lime". Clays and Clay Minerals ,68(5), 2020, pp.499-512. 